\title{
ОБЗОРЫ
}

\section{Влияние интеллектуального капитала на финансовые решения компаний}

\author{
Тюрина Е.И. ${ }^{20}$, Иванинский И.О. ${ }^{21}$
}

Настоящая статья представляет собой теоретический обзор существующих подходов к анализу влияния интеллектуального капитала (ИК) на принятие финансовых решений компаний, как важного фактора, влияющего на их стоимость. Влияние ИК возрастает в процессе перехода $к$ экономике знаний. Включение факторов ИК в классические модели позволяет корректней отразить изменившуюся сущность деятельности компаний.

На развитых рынках США и Западной Европь активно исследуется взаимосвязь между ИК и принимаемыми финансовыми ремениями. Подобные исследования практически отсутствуют по развивающимся рынкам капитала. Настоящая статья демонстрирует возможности и результаты учета ИК при проведении подобных исследований.

Результаты анализа ранних исследований показывают, что уровень долга в совокупном капитале компаний, а также процент чистой прибыли, распределяемой в виде дивидендов, находятся в обратной зависимости от величины ИК компаний. Однако более поздние исследования, в которых рассматривается эффективность использования ИК, демонстрируют наличие прямой зависимости между эффективностью использования ИК и размером финансового рычага.

\section{JEL: G12, G32}

Ключевые слова: интеллектуальный капитал, финансовые решения, структура капитала, корпоративные финансы

\section{Введение}

В условиях перехода к экономике знаний интеллектуальный капитал (ИК) становится полноценным элементом финансовой архитектуры компаний и источником долгосрочного конкурентного преимущества. Процесс создания стоимости многих современных компаний, инновационных изначально, построен исключительно на ИК, однако традиционные теории не включают ИК в модели принятия стратегических финансовых решений.

Учет ИК в рамках исследования финансовых решений позволяет корректней моделировать деятельность компаний. Данное предположение подтверждается большим количеством исследований на развитых рынках США и Западной Европы, представленных в научной литературе. Однако на развивающихся рынках капитала, и на российском рынке в частности, выбранная тема в настоящее время раскрыта весьма ограниченно.

Под финансовыми решениями в настоящей статье понимаются структура капитала и политика выплат компаний. Структура капитала является важнейшим элементом финансовой политики. Она оказывает влияние на стоимость компании через средневзвешенные затраты на капитал, а также выгоды от использования финансового рычага. Политика выплат является механизмом перераспределения стоимости, созданной

\footnotetext{
20 Преподаватель кафедры экономики и финансов фирмы ГУ ВШЭ, н.с. лаборатории корпоративных финансов.

${ }^{21}$ Стажер-исследователь лаборатория корпоративных финансов.
} 
компанией, к ее акционерам.

Настоящая статья имеет обзорный характер и демонстрирует, как включение ИК в качестве фактора, влияющего на принятие финансовых решений компаний, может повлиять на результаты исследования. Кроме того, мы демонстрируем разницу получаемых результатов в зависимости от способа измерения ИК.

\section{Роль интеллектуального капитала и его компонентов в деятельности компании}

Понятие ИК встречается еще в работах середины 80-х годов XX века. Однако широкое распространение концепция ИК получила только в 1990-х годах. Распространение концепции связано с появлением огромных компаний, таких как Google, Microsoft, Apple и прочие, для которых он является единственным производственным ресурсом.

Переход к экономике знаний привел к четырем крупным изменениям в принципах деятельности фирм. Во-первых, снижается зависимость компаний, работающих в экономике знаний, от традиционных форм капитала. Во-вторых, новые технологии позволяют снизить стоимость коммуникации с потребителями, что открывает новые возможности для недавно созданных компаний. В-третьих, растущая конкуренция ведет к потребности в непрерывных инновациях, что увеличивает важность ИК. В-четвертых, происходит снижение зависимости сотрудников от компаний [Zingales, 2000].

Таким образом, фирмы в новой экономике функционируют в условиях обострившейся конкуренции, сопровождающейся повышенной зависимостью от ИК и сотрудников как основных носителей этого капитала. Неправильное отношение к сотрудникам зачастую ведет к проблемам в бизнесе компаний. Показательна история рекламного агентства «Саачи и Саачи».

В 1994 году Морис Саачи, генеральный директор, назначил себе многомиллионный бонус. Фонды прямых инвестиций, контролировавшие $30 \%$ акций компании, были резко против подобного решения. Акции падали в цене на протяжении нескольких лет и, с точки зрения фондов, генеральный директор не заслужил бонус. На собрании акционеров Саачи было отказано в его получении. Подобное решение не устроило Саачи, и вскоре он покинул фирму вместе с рядом ключевых менеджеров. Спустя некоторое время Саачи вместе с братом основал новое рекламное агентство, куда перешла значительная часть ключевых клиентов агентства «Саачи и Саачи», а оно, в свою очередь, вынуждено было сменить название. Таким образом, бизнесу и акционерам был нанесен ущерб [Zingales, 2000].

При описании изменений в принципах деятельности компаний уже было упомянуто понятие человеческого капитала, как компонента ИК. Однако человеческий капитал не является его синонимом. ИК компании - это сложный показатель. Рассмотрим структуру ИК и роль отдельных его компонентов.

\section{Компоненты интеллектуального капитала}

Традиционно выделяют три компонента ИК: человеческий капитал, клиентский капитал и процессный капитал [Ashton, 2005; Bontis, 1998; Robb, Robinson, 2009]. 


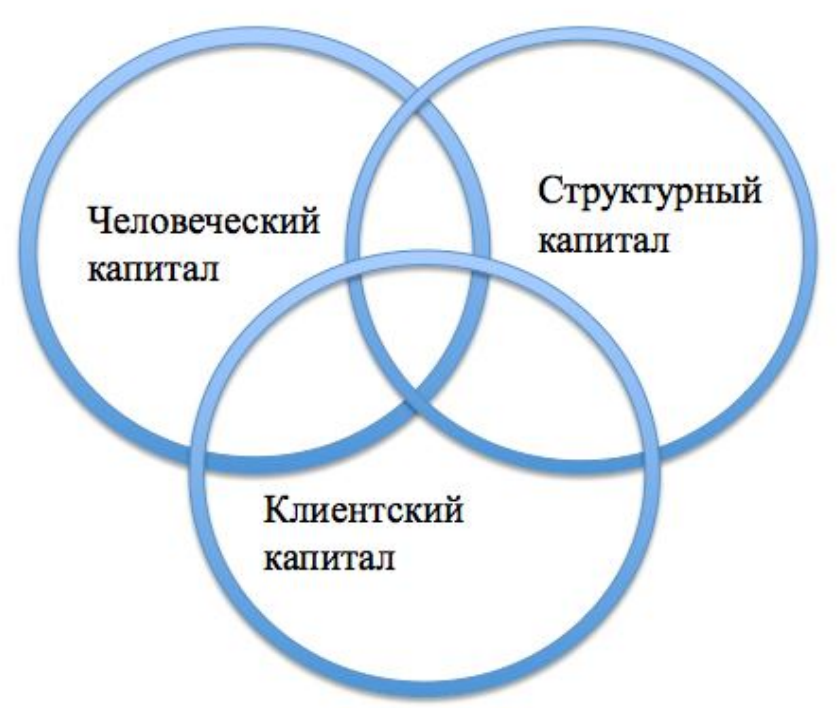

Рисунок 1. Виды интеллектуального капитала

Источник: [Tahvanainen, Hermans, 2005].

\section{Человеческий капитал}

Человеческий капитал - совокупность знаний, навыков и опыта персонала, работающего в компании [Ashton, 2005; Becker, 1964; Bettis, 1981\$ Edvinsson, Malone, 1997].

Важность человеческого капитала была отмечена еще в 1960-х годах нобелевским лауреатом Герри Беккером. Затраты на образование и тренинги приводят к росту человеческого капитала, который невозможно отделить от человека [Becker, 1964].

Таким образом, расходы на персонал компании стоит рассматривать скорее как инвестиции, нежели как затраты. Рассмотрение расходов на персонал в качестве инвестиций ведет к тому, что изменяются принципы работы с персоналом и схемы мотивации [Hussi, 2004; Jensen, Meckling, 1976; Love, 2009]. Типичный пример компании, добившейся выдающихся успехов, - MacDonald's. Успешность компании во многом определяется именно политикой персонала [Love, 2009].

\section{Клиентский капитал}

Клиентский капитал - взаимоотношения компании с клиентами, выражающиеся в их лояльности к продуктам и услугам данной конкретной компании [Ashton, 2005; Bettis, 1981; Edvinsson, Malone, 1997].

Компании, нацеленные на долгосрочные отношения с клиентами, несут высокие расходы на рекламу и маркетинг. Удачная маркетинговая кампания в сочетании с удачным продуктом могут привести к феноменальным результатам. Типичный пример компании, успешно проводящей маркетинговую политику, - Apple, в частности в период с 2000 года года появления iPod. Грамотный, маркетинг позволил сделать iPod иконой промышленного дизайна и привел к возрастанию популярности техники Apple [Прокеш, 2009].

Однако существуют и примеры неудачных маркетинговых решений. Показателен пример сети кофеен Starbucks. Некоторое время назад в кофейнях стали подавать горячий завтрак, что сопровождалось широкой рекламной кампанией. Однако в результате выручка кофеен упала. Причина этой «аномалии» крылась в том что в процессе приготовления горячей еды из кофеен исчез запах кофе, любимый посетителями. Горячие завтраки в срочном порядке отменили [Джонсон, 2009]. 


\section{Структурный капитал}

Структурный капитал - совокупность информации и знаний, накопленных в компании и существующих независимо от работников данной компании. Структурный капитал компании - это знания, которые остаются в ней, когда персонал уходит [Bontis, 1998; Pulic, 2004].

Этот компонент включает в себя базы данных, распорядки и т.д. Структурный капитал существенно зависит от человеческого, на основании которого он создается. Компании, ориентированные на долгосрочное развитие, уделяют существенное внимание структурному капиталу, стремясь формализовать процессы и схемы принятия решений. Показателен пример консалтинговых компаний, таких как McKinsey\&Company и Boston Consulting Group. Их деятельность на $100 \%$ осуществляется людьми, однако в компаниях созданы инструменты анализа (такие как система 7S McKinsey или матрица BCG), позволяющие продолжать работу вне зависимости от смены кадров [Фон Крог, Райч, 2010; Roos et al., 1998].

Однако устойчивость - это не единственная составляющая успеха. Залог долгосрочного успеха - инновации. Научные разработки ведутся сотрудниками компании, но патент является ее собственностью. Примерами компаний, секрет успеха которых объясняется именно инновациями, могут служить General Electric, IBM, Intel и другие компании, работающие в области высоких технологий. Важность инноваций возросла с переходом в эру компьютеров и Интернета [Bontis, 1998; Edvinsson, Malone, 1997; Holder et al., 1998]. Для создания инноваций необходимы расходы на НИОКР, которые должны рассматриваться как инвестиции. Показательно, что МСФО идут по пути признания расходов на НИОКР в качестве инвестиций. Инновационную составляющую структурного капитала иногда рассматривают в качестве отдельного вида капитала [Edvinsson, Malone, 1997; Holder et al., 1998; Lev, 2001; Pulic, 2004].

Обратим внимание на важнейший факт, связанный с ИК. Практически все его компоненты возникают при взаимодействии компании со своими стейкхолдерами. Так, клиентский капитал - это, по сути, взаимоотношения с потребителями; процессный капитал (включая инновационную составляющую) и человеческий капитал - это взаимоотношения компании с сотрудниками и т.д.

Прежде чем перейти непосредственно к исследованиям влияния ИК на финансовые решения, остановимся на роли стейкхолдеров в деятельности компаний.

\section{Влияние стейкхолдеров на деятельность компании и принимаемые финансовые решения}

Традиционная теория фирмы рассматривает компанию с точки зрения акционеров и кредиторов. Однако в современных условиях деятельность фирмы во многом определяется действиями более широкого круга стейкхолдеров.

Помимо акционеров и кредиторов основными стейкхолдерами принято считать потребителей, поставщиков, сотрудников компании, дистрибьюторов и (иногда) органы государственной власти [Cornell, Shapiro, 1987; Zingales, 2000].

Между двумя этими группами существует два ключевых отличия. Во-первых, акционеры и кредиторы предоставляют компаниям капитал и непосредственно принимают участие в распределении их доходов. Остальные стейкхолдеры участвуют в текущей деятельности компании и непосредственно не принимают участие в распределении результатов деятельности. Вторая группа стейкхолдеров имеет доступ к результатам деятельности компании только в случае банкротства [Cornell, Shapiro, 1987].

Поскольку вторая группа предъявляет требования к результатам деятельности компании только в случае банкротства, может сложиться впечатление, что в повседневной деятельности компании она не оказывает влияния на денежные потоки. Это заблуждение 
привело к тому, что эти стейкхолдеры практически не изучались вне контекста банкротства.

Второе отличие двух групп состоит в «структуре контрактов» с компанией [Cornell, Shapiro, 1987]. Взаимодействие акционеров и кредиторов с компанией носит явный характер. Компании предоставляется капитал в обмен на обязательства выплатить процент по долгу или распределить остаточный доход в виде дивидендов. Взаимодействие же со «второй группой стейкхолдеров» носит более сложный характер. Помимо явной части контракта между компанией и стейкхолдерами существуют неявные взаимоотношения. Для разных стейкхолдеров эти отношения выглядят по-разному. Так, в частности, покупатель, приобретая товар, ожидает от компании надлежащего уровня сервиса на протяжении всего периода обладания товаром; поставщик, поставив компании сырье, отвечает перед компанией за качество продукта, и т.д. [Cornell, Shapiro, 1987; Zingales, 2000].

У неявных взаимоотношений существует ряд особенностей. Во-первых, они неотделимы от явных. Например, покупатель не может ожидать от фирмы предоставления сервиса, не приобретя товар. Во-вторых, риск, связанный с ними, трудно хеджировать. Сотрудник предприятия имеет гарантию, что он не будет уволен без причины. Однако он не может продать или приобрести аналогичную гарантию. В-третьих, невыполнение компанией неявных обязательств не находит отражения в отчетности. Однако дефолт по неявным обязательствам не менее важен, чем по явным. Этот факт имеет важные последствия с точки зрения изучаемой темы, эти последствия будут далее.

Описанные выше отличия двух групп стейкхолдеров ведут к важным выводам. Вопервых, стейкхолдеры, отличные от акционеров и кредиторов, оказывают значимое влияние на деятельность компании вне зависимости от того, проходит ли она в данный момент через процедуру банкротства. Во-вторых, неявные взаимоотношения компании со стейкхолдерами не менее важны, чем явные. Следовательно, учет влияния стейкхолдеров, отличных от кредиторов и акционеров, на деятельность компании позволит по-новому взглянуть на принятие финансовых решений компанией.

Влияние ИК на структуру капитала компаний основано на учете влияния стейкхолдеров на деятельность компаний. Основоположниками этого подхода принято считать ученых Корнелла и Шапиро. В своей ставшей классической статье «Сorporate Stakeholders and Corporate Finance» они утверждают, что учет интересов стейкхолдеров, отличных от акционеров и кредиторов, ведет к новым интерпретациям классических проблем корпоративных финансов [Cornell, Shapiro, 1987].

Суть этого подхода можно кратко описать следующим образом. Компания, продавая продукт или услугу, не может ограничиваться учетом только полученных доходов и затрат. Компания должна учитывать долгосрочный характер взаимоотношений с клиентом и принимать во внимание возможные будущие доходы и обязательства [Cornell, Shapiro, 1987]. Будущие (неявные) доходы возникают, например, в результате того, что компания, продав качественный продукт, получает лояльность покупателя и шанс, что покупатель и в дальнейшем будет пользоваться ее продуктами. Неявные обязательства, например, проявляются в потере репутации в случае низкого качества продукта [Cornell, Shapiro, 1987]. Разница между накопленными неявными доходами и обязательствами формирует чистый организационный капитал компаний (net organizational capital, NOC). Ha рисунке ниже представлено предложенное авторами отражение изменений в балансе компаний. 


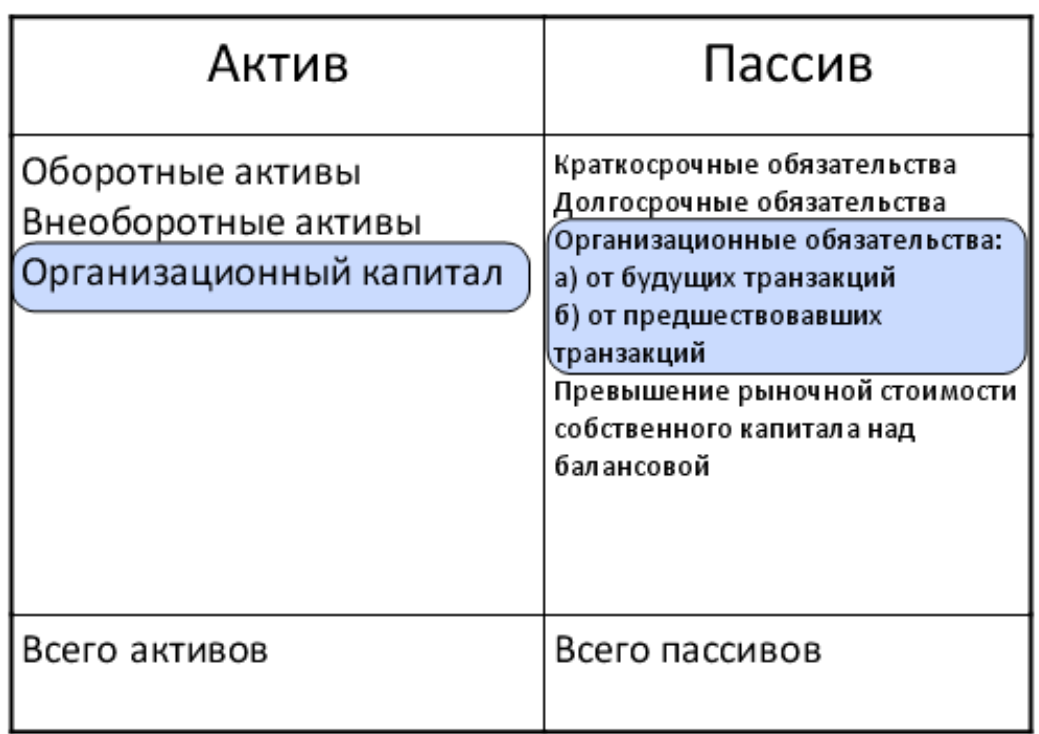

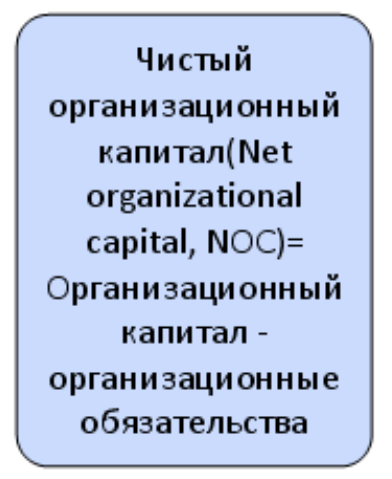

Рисунок 2. Изменение баланса компании при учете чистого оборотного капитала

Источник: [Cornell, Shapiro, 1987].

Подобные изменения сказываются на стабильности денежных потоков компании и принимаемых финансовых решениях. Вероятность незапланированных выплат заставляет компанию откладывать использование наиболее дешевых источников финансирования, которыми традиционно считаются наличные деньги и банковские кредиты, и переходить к более дорогому способу - привлечению дополнительного акционерного капитала. Кроме того, это приводит к тому, что компания не может брать на себя обязательства перед акционерами по выплате дивидендов, что при прочих равных условиях заставляет компанию снижать процент чистой прибыли, распределяемой в виде дивидендов [Cornell, Shapiro, 1987]. Таким образом, возросшая роль ИК приводит к тому что компания имеет меньший размер финансового рычага.

\section{Исследования влияния интеллектуального капитала на структуру капитала компаний}

Теоретическая концепция, предложенная Корнеллом и Шапиро, чрезвычайно интересна, однако ее очень трудно проверить эмпирически. Чистый организационный капитал практически невозможно измерить. Это вынуждает исследователей искать косвенные способы измерения.

Бартон и Хилл [Barton, Hill, 1989] проводили исследование влияния чистого организационного капитала на уровень долга в совокупном капитале компаний. Авторы измеряли сконцентрированность бизнеса как отношение объема выручки компании, получаемой от основного бизнеса, к ее общей выручке. Они проводили исследование на данных 179 компаний из списка Fortune 500 за 1970-1974 годы. В результате проведенного исследования авторы пришли к выводу что уровень долга в совокупном капитале компании находится в обратной зависимости от уровня чистого организационного капитала компании.

Аналогичные исследования, в которых в качестве меры чистого организационного капитала использовался показатель концентрации бизнеса, подтверждают теорию Корнелла и Шапиро. Однако показатель концентрации бизнеса является достаточно спорным способом измерения чистого организационного капитала.

Более современные исследования подтверждают ранее полученные результаты. Так, в частности, в работе Херманс и Кулвик [Hermans, Kulvik, 2004] было оценено влияние человеческого, структурного и клиентского капитала на предпочтительные источники финансирования для фармацевтических компаний Финляндии в 2002 году. Выборка 
исследования состояла из 84 компаний. В результате проведенного исследования авторами было установлено, что большую часть финансирования рассмотренные компании получают от фондов прямых инвестиций и венчурных фондов. Долговое финансирование используется в значительно меньшей степени. Авторы объясняют полученный результат высокой рискованностью деятельности средних и малых фирм в такой высокотехнологичной отрасли, как фармацевтика.

Результаты, во многом аналогичные результатам Херманса и Кулвика, были получены в работе Аудретша и Леманна [Audretsch, Lehmann, 2003]. Авторы исследовали источники финансирования молодых инновационных фирм в Германии в период с 1997-го по 2002 год. Они также разделили ИК на человеческий, структурный и клиентский. В результате проведенного исследования было выявлено, что все рассмотренные компоненты ИК являются факторами, обуславливающими выбор недолговых форм финансирования деятельности (венчурные инвестиции и собственные средства).

Сходные результаты были получены в исследованиях, проведенных для выборок, состоящих не только из компаний из высокотехнологичных отраслей.

Так, в частности, Роб и Робинсон [Robb, Robinson, 2009] изучали источники финансирования новых фирм в США, созданных в 2004 году. Выборка состояла из 2168 фирм, работающих в различных отраслях. Авторы установили, что, хотя преимущественным источником финансирования новых фирм является банковский долг, наличие на балансе фирмы нематериальных активов негативно сказывается на возможности привлечения долгового финансирования. Проведенное авторами исследование имеет два основных ограничения: во-первых, были рассмотрены только вновь созданные фирмы; во-вторых, ИК не всегда тождественен нематериальным активам, отраженным на балансе.

Спорледер и Mocc [Sporleder, Moss, 2001] получили похожие результаты при анализе структуры капитала компаний сельскохозяйственной отрасли США. Группа показателей, связанных с ИК, представлена долей нематериальных активов в общих активах компании и отношением затрат на НИОКР к выручке компании. В результате проведенного анализа авторы установили, что размер финансового рычага находится в обратной зависимости от доли нематериальных активов. Отношение затрат на НИОКР к выручке, как и в более раннем исследовани Бартон [Barton et al., 1989], не оказывает значимого влияния на уровень финансового рычага.

Рассмотренные исследования проводились в различных странах и различных отраслях. Были использованы разные показатели для описания ИК. Часть исследователей рассматривают ИК в целом, в то время как другая часть - лишь отдельные его компоненты. Однако, несмотря на различия, исследования подтверждают теорию Корнелла-Шапиро.

\section{Исследования влияния интеллектуального капитала на политику выплат компаний}

Влияние ИК на политику выплат во многом схоже с влиянием на структуру капитала и так же опирается на теорию Корнелла-Шапиро [Edvinsson, Malone, 1997].

Однако, несмотря на то что теоретическая концепция разработана, эмпирических исследований по данной тематике практически не проводилось. Одно из немногих подобных исследований - исследование Холдер [Holder et al., 1998]. В исследовании авторы, как и Бартон [Barton et al., 1989], пользуются коэффициентом концентрации бизнеса для измерения величины чистого оборотного капитала. Выборка исследования состоит из 477 американских компаний в период 1983-1990 годов.

Авторы установили, что доля чистой прибыли, распределяемая в виде дивидендов, находится в зависимости, обратной от размера чистого организационного капитала. Полученный результат подтверждает концепцию влияния стейкхолдеров на деятельность компании, предложенную в работе Корнелл и Шапиро [Cornell, Shapiro, 1987].

В более поздних исследованиях влияние стейкхолдеров на политику выплат компании, 
как правило, включается косвенным образом. В целом результаты свидетельствуют о том, что в случае, когда стейкхолдеры, не являющиеся собственниками, имеют влияние на компанию, размер прибыли, распределяемой в виде дивидендов, ниже.

Так, в частности, Броунер и др. [Brounen et al., 2004] в результате социологического опроса, проведенного среди 313 CFO Великобритании, Нидерландов, Франции и Германии, установили, что компании, нацеленные на интересы своих стейкхолдеров, как правило, уделяют меньшее внимание размеру выплачиваемых дивидендов. При этом наиболее важными стейкхолдерами компаний участники исследования назвали потребителей, сотрудников и менеджмент компании. Акционеры оказались в большинстве стран по значимости лишь на четвертом месте [Bøhren, Josephsen, 2009].

В исследовании Ла Порта и др. [La Porta et al., 2000] авторы показывают, что в странах Западной Европы, в которых законодательство направлено на защиту интересов стейкхолдеров, компании, как правило, выплачивают меньший процент прибыли в виде дивидендов. Схожий результат получают Реннебуг и Жиладжи [Renneboog, Szilagyi, 2006]. В исследовании авторы рассматривают законодательство страны с помощью даммипеременной. Полученный результат показывает, что ориентация на стейкхолдеров, при прочих равных, оказывает отрицательное влияние на процент прибыли, распределяемый в виде дивидендов.

Существующие исследования лежат в русле агентской теории и изучают конфликт между акционерами и другими стейкхолдерами компании - главным образом кредиторами и менеджментом. Исследования косвенно подтверждают выводы теории стейкхолдеров Корнелла и Шапиро, но для проверки требуются дополнительные исследования.

\section{Заключение}

Включение ИК в исследования финансовых решений компаний позволяет более полно отразить их деятельность. Влияние ИК резко возрастает при переходе к экономике знаний, что является фактором, обуславливающим необходимость его включения в модель.

Рассмотрение влияния ИК на деятельность компаний, а значит, и на принимаемые ими финансовые решения, происходит в рамках теории влияния на компанию ее стейкхолдеров, предложенной Корнеллом и Шапиро.

Исследования влияния ИК на структуру капитала в целом подтверждают выводы теории стейкхолдеров о том, что уровень долга в совокупном капитале компании находится в обратной зависимости от величины ИК компании. Однако более поздние исследования обнаруживают наличие прямой зависимости между эффективностью использования ИК компании и размером ее финансового рычага.

Влияние стейкхолдеров компании на ее политику выплат на настоящий момент остается малоизученным. Большинство современных исследований рассматривают эту проблему в рамках агентской теории и с учетом интересов стейкхолдеров косвенным образом. Ограниченность изученности данной тематики, особенно на развивающихся рынках капитала, открывает широкие возможности для проведения исследования в дальнейшем.

\section{Список литературы}

1. Джонсон М., Кристенсен К., Кагерманн Х. Обоснование бизнес-модели // Harvard Business Review - Russia. 2009. № 2. C. 62-74.

2. Кон Д., Канцебах Й., Влак Г. Новаторы от Бога: найти и воспитать // Harvard Business Review - Russia. 2009. № 3. С. 56-66.

3. Прокеш С. Управлять изменениями. Рецепты от GE //Harvard Business Review Russia. 2009. № 6. C. 91-108.

4. Фон Крог Г., Райч С. Все внимание - нескольким инновационным идеям // Harvard business review - Russia. 2010. № 1. C. 20-21. 
5. Ashton, R.H. (2005), Intellectual capital and value creation: a review, Journal of accounting literature, 24 (2005) 53-134.

6. Audretsch, D.B., Lehmann E. E. (2002), Financing High-Tech Growth: The Role of Debt and Equity, Working paper 2002.

7. Barton, S.L., Hill, N.C., Sundaram S. (1989), An Empirical Test of Stakeholder Theory Predictions of Capital Structure, Financial Management, (Spring 1989) 36-44.

8. Becker, G.S. (1964), Human Capital, National Bureau of Economic Research, distributed by Columbia University Press, New York, NY.

9. Bettis, R.A. (1981), Performance Differences in Related and Unrelated Diversified Firms, Strategic Management Journal, (April/June 1981) 379-393.

10. Bøhren, O., Josephsen, M.G., Steen P.E. (2009), Dividends and stakeholder conflicts: A cleaner test, EFA Bergen Meetings Paper.

11. Bontis, N. (1998), Intellectual capital: an exploratory study that develops measures and models, Management Decision, 36(2) (1998) 63-79.

12. Cornell, B., Shapiro, A.C. (1987), Corporate Stakeholders and Corporate Finance, Financial Management, (Spring 1987) 5-14.

13. Edvinsson, L., Malone, M. (1997), Intellectual Capital: Realizing Your Company's True Value by Finding Its Hidden Brainpower. - HarperCollins.

14. Faulkender, M., Peterson, M. (2006), Does the source of capital affect capital structure? Review of Financial Studies, 19 (2006) 45-79.

15.Hermans, R., Kulvik, M. (2004), Measuring intellectual capital and sources of equity financing - value platform perspective within the Finnish biopharmaceutical industry, Int. J. Learning and Intellectual Capital, 3(1) (2004).

16. Holder, M. E., Landgrehn, F. W., Hexter, J. L. (1998), Dividend policy determinants: an investigation of the influences of stakeholder theory, Financial Management, 27(3) (1998) 73-82.

17. Hussi, T. (2004), Reconfiguring knowledge management. Combining intellectual capital, intangible assets and knowledge creation, Journal of Knowledge Management, 8(2) (2004) $36-52$.

18. Jensen, M., Meckling, W. (1976), The Theory of Firm: Managerial Behavior, Agency Costs and Capital Structure, Journal of Financial Economics, 3 (1976) 305-360.

19. La Porta, R., Lopez-de-Silanes, F., Shleifer, A., Vishny, R. (2000), Investor protection and corporate governance, Journal of Financial Economics, 58 (2000) 3-27.

20.Lev, B. (2001), Intangibles: Management, Measurement, and Reporting, Brooking Institute Press.

21.Love, J.S. (2009), McDonalds - Behind the Arches Customer Acquisition and Retention. URL: http://www.scribd.com/doc/11520753/Marketing-Strategies-of-McDonalds (2009).

22.Pulic, A. (2004), Intellectual capital - does it create or destroy value? Measuring Business Excellence, 8(1) (2004) 62-68.

23. Renneboog, L., Szilagyi, P.G. (2006), How relevant is dividend policy under low shareholder protection? Tilburg University Working paper.

24. Robb, A. M., Robinson, D. T. (2009), The Capital Structure Decisions of New Firms, Fuqua School of Business, Duke University Working paper.

25. Roos, J., Roos, G., Dragonetti, N.C., Edvinsson, L. (1998), Intellectual Capital: Navigating in the New Business Landscape, New York University Press.

26. Rumelt, R.P. (1974), Strategy, Structure and Economic Performance, Cambridge, MA, Harvard University Press.

27. Sporleder, T.L., Moss, L.E. (2001), Capital structure decisions of U.S. - based food processing firms: a transaction cost economic perspective, Annual Meeting of the Western Coordinating Committee on Agribusiness, Las Vegas, Nevada.

28.Zingales, L. (2000), In Search of New Foundations, The Journal of Finance, 55(4) (2000) $1623-1653$. 